\title{
NODUlAÇÃO, ACÚMUlO DE NITROGÊNIO NO SOLO E NA PLANTA, E PRODUTIVIDADE DE SOJA EM SOLO TRATADO COM LODO DE ESTAÇÃO DE TRATAMENTO DE RESÍDUOS INDUSTRIAIS (1)
}

\author{
MAUREL BEHLING $\left({ }^{2}\right)$; FABIANA DE CARVALHO DIAS $\left({ }^{2}\right)$; NELSON MOURA BRASIL DO \\ AMARAL SOBRINHO $\left({ }^{3 * 4}\right)$; CLARICE DE OLIVEIRA $\left({ }^{3}\right)$; NELSON MAZUR $\left({ }^{3}\right)$
}

\begin{abstract}
RESUMO
Como conseqüência do avanço industrial, nas últimas décadas, grande quantidade e variedade de resíduos tem sido gerado. Uma alternativa para a disposição final deste material tem sido sua aplicação ao solo. O uso destes materiais na agricultura tornou-se alternativa atrativa, tanto do ponto de vista de reciclagem de nutrientes, quanto do ponto de vista econômico. O trabalho foi desenvolvido com o objetivo de avaliar o efeito da adição de lodo de Estação de Tratamento de Resíduos Industriais (LETRIP) na nodulação, no acúmulo de nitrogênio e na produtividade da cultivar de soja Celeste em uma área de Planossolo. Os tratamentos foram compostos pelas doses de 0, 25, 50 e $100 \mathrm{Mg}$ ha $^{-1}$ de lodo. O delineamento experimental foi em blocos ao acaso, com quatro tratamentos e três repetições, totalizando 12 parcelas experimentais. A semeadura da soja (Glycine max (L.) Merr.) foi realizada de 13 a 20 de janeiro de 2005, 40 dias após a aplicação do lodo. O número total de nódulos foi reduzido nas doses de 25 e $50 \mathrm{Mg} \mathrm{ha}^{-1}$ de LETRIP. Produtividade superior a $4100 \mathrm{~kg} \mathrm{ha}^{-1}$ foi obtida na maior dose do lodo com um incremento mínimo de $1224 \mathrm{~kg} \mathrm{ha}^{-1}$ em relação à testemunha, demonstrando o potencial desse resíduo para utilização agrícola, em substituição aos adubos minerais, sendo necessário um cuidado especial quanto às relações de equilíbrio entre $\mathrm{N}$-orgânico e $\mathrm{N}$-mineral $\left(\mathrm{N}-\mathrm{NH}_{4}^{+}+\mathrm{N}-\mathrm{NO}_{3}^{-}\right)$.
\end{abstract}

Palavras-chave: Glycine Max, biossólido, carbono orgânico, nitrificação, lixiviação.

\section{ABSTRACT \\ NODULATION, ACCUMULATION OF SOIL AND PLANT NITROGEN, AND SOYBEAN YIELD IN SOIL AMENDED WITH TREATED INDUSTRIAL SLUDGE}

As a consequence of the industrial progress in the last decades a great amount and variety of residues has been generated. An alternative for the final disposition of this material has been its application to the soil. The use of these materials in the agriculture became an attractive alternative as from the point of view of recycling of nutrients as well as of the economical point of view. This research was developed with the objective of evaluating the effect of industrial sludge addition (LETRIP) in accumulation of nitrogen, nodulation and in soybean yield of Celeste cultivar in a Planossolo area (Fragiudult) of UFRRJ. The treatments were set by doses of $0,25,50$ and $100 \mathrm{Mg} \mathrm{ha}^{-1}$ of sludge in a randomized block design, with three replications (12 plots). The soybean was planted from January 13th to 20th, 2005, approximately 40 days after sludge application. The total number of nodules was reduced in the doses of 25 and $50 \mathrm{Mg} \mathrm{h}^{-1}$ of LETRIP. Productivity greater than $4100 \mathrm{~kg} \mathrm{ha}^{-1}$ was obtained with the highest dose of sludge and with a minimum increment of $1224 \mathrm{~kg} \mathrm{ha}^{-1}$ when compared to the testimony, showing the potential of the residues for substituting mineral fertilizers in agricultural. However, caution is necessary when equilibrating rations between organic and mineral $\mathrm{N}\left(\mathrm{N}-\mathrm{NH}_{4}^{+}+\mathrm{N}-\mathrm{NO}_{3}^{-}\right)$, what should be monitored with the time.

Key words: Glycine Max, biosolids, organic carbon, nitrification, leaching.

( ${ }^{1}$ ) Parte da tese de mestrado do primeiro autor, apresentada ao Departamento de Solos da Universidade Federal Rural do Rio de Janeiro (UFRRJ), Seropédica (RJ). Recebido para publicação em 25 de setembtro de 2007 e aceito em 11 de fevereiro de 2009.

$\left(^{2}\right)$ Mestre em Agronomia Ciência do Solo - CPGA-CS da UFRRJ. E-mail: diasfac@yahoo.com.br

$\left({ }^{3}\right)$ Departamento de Solos, Universidade Federal Rural do Rio de Janeiro (UFRRJ), 23890-000 Seropédica (RJ). E-mail: nelmoura@ufrrj.br $\left(^{*}\right)$ Autor correspondente; nelmazur@ufrrj.br

$\left({ }^{4}\right)$ Bolsista do CNPq. 


\section{INTRODUÇÃO}

O avanço industrial, nas últimas décadas, tem gerado grande quantidade e variedade de resíduos, causando sérios problemas ambientais. Com o aumento dos custos dos fertilizantes comerciais e a escassez de áreas disponíveis próximas aos grandes centros urbanos para o despejo dos resíduos industriais e urbanos, o uso desse material na agricultura tornou-se alternativa atrativa, tanto do ponto de vista de reciclagem de nutrientes, quanto do ponto de vista econômico (Mesquita, 2002). Muitos destes resíduos possuem quantidades apreciáveis de nutrientes para as culturas como N, $\mathrm{P}$ e $\mathrm{K}$, podendo, desse modo, ser usado como fertilizante. O reaproveitamento de determinados resíduos pode proporcionar, aos agricultores, a oportunidade de reduzir os custos com fertilizantes inorgânicos e a solução parcial para a disposição deste material, pelos órgãos responsáveis.

A utilização de biossólidos, com finalidade agrícola, requer um acompanhamento do processo de mineralização do N no solo, uma vez que excessivas quantidades de nitrato, poderão por meio dos processos de lixiviação e desnitrificação, contaminar águas subterrâneas ou provocar o desprendimento de óxido nitroso (Vieira, 2004; Alves et al., 2000). A dinâmica do nitrogênio no sistema solo-planta é bem complexa e difícil de ser medida, pois envolve muitos processos de transformações e perdas do nitrogênio, os quais são influenciados por outros processos igualmente complexos, como atividade de microrganismos do solo, fluxos de água, etc. (Bergamasco et al., 2002).

A mineralização é resultante da degradação de formas orgânicas do nitrogênio exercida pela atividade microbiana durante os cultivos, disponibilizando nitrogênio mineral às plantas. De acordo com os dados compilados de PAUL e CLARK (1996), a contribuição do N-mineralizado aos cultivos, durante o ano, é cerca de 20 vezes a da fixação biológica do nitrogênio atmosférico. A soja pode utilizar rapidamente tanto o $\mathrm{N}$ simbiótico quanto o disponível no solo. Quando o suprimento ocorre em quantidade excedente às necessidades para o crescimento das plantas, pode haver interferência do $\mathrm{N}$ na eficiência da fixação simbiótica (Allos e BARTHOLEMEU, 1959; Weber, 1966).

A Petroflex Indústria e Comércio S/A é produtora de borracha sintética (SBR). Na produção de borracha, gera-se um volume de resíduos considerável, e a empresa vem buscando, nos últimos anos, soluções para eliminar seu passivo ambiental e a manutenção dos certificados de suas unidades industriais pela norma ISO-14000, obtidos desde 1996
(Miranda Neto, 2002). O reaproveitamento agrícola dos resíduos gerados pela indústria Petroflex vai diminuir o volume a ser disposto em aterros, reduzindo a poluição do solo e das águas subterrâneas por metais pesados e nitrato. O lodo da Estação de Tratamento de Resíduos Industriais da Petroflex (LETRIP) é uma fonte de nutrientes e matéria orgânica para as plantas.

O presente trabalho teve como objetivo avaliar o efeito da adição deste resíduo nas relações de equilíbrio entre $\mathrm{N}$-orgânico e $\mathrm{N}$-mineral do solo; na nodulação e produtividade da cultura da soja (cultivar Celeste), submetida a doses do resíduo LETRIP, em área de Planossolo, no Rio de Janeiro.

\section{MATERIAL E MÉTODOS}

O experimento foi realizado na área experimental da Universidade Federal Rural do Rio de Janeiro, localizada em Seropédica (RJ) a $22^{\circ} 47^{\prime}$ de latitude Sul e $43^{\circ} 40^{\prime}$ de longitude Oeste, a aproximadamente $80 \mathrm{~km}$ da cidade do Rio de Janeiro (RJ). Foi desenvolvido em condições de campo, em área de relevo plano ( $<3 \%$ de declividade), cujo solo foi classificado como Planossolo Háplico eutrófico. As características físicas e químicas do solo em estudo estão relacionadas na tabela 1.

Segundo a classificação de Köppen, a região possui clima tipo Aw (clima tropical de inverno seco e verão chuvoso). A temperatura média do ano 2005 foi de $24,21^{\circ} \mathrm{C}$, sendo janeiro e fevereiro os meses mais quentes, e os mais frios, junho e julho, com temperatura máxima absoluta ultrapassando os $38^{\circ} \mathrm{C}$ e a mínima absoluta não sendo inferior a $11^{\circ} \mathrm{C}$. Verificam-se valores acima de $65 \%$ ao longo do ano, na umidade relativa do ar. A precipitação pluviométrica total, em 2004, foi de $1.222 \mathrm{~mm}$ e o total de chuvas do mês mais seco não ultrapassou $50 \mathrm{~mm}$, dados do Posto Agrometeorológico da Estação Ecologia Agrícola, Km 47, Pesagro-Rio/INMET.

As amostras do LETRIP foram coletadas, segundo a ABNT/NBR 10.007 (2004) e, após coleta, as amostras foram secas ao ar, destorroadas, homogeneizadas e passadas em peneira de $2 \mathrm{~mm}$ de malha. Com a análise do lodo, constataram-se as seguintes características morfológicas: forma sólida; cor cinza-escuro e umidade de $80 \%$. Os resultados das análises químicas, em base seca do lodo, foram os seguintes: $\mathrm{pH}_{(\mathrm{H} 2 \mathrm{O})}$ : 7,5; C-orgânico: 204,0 $\mathrm{g} \mathrm{kg}^{-1}$; N-total: $15,11 \mathrm{~g} \mathrm{~kg}^{-1}$; $\mathrm{Ca}+\mathrm{Mg}: 12,62 \mathrm{~g} \mathrm{~kg}^{-1}$; P: 18,92 $\mathrm{g} \mathrm{kg}^{-1}$; $\mathrm{K}: 5,76 \mathrm{~g} \mathrm{~kg}^{-1}$; Cd: $0,90 \mathrm{mg} \mathrm{kg}^{-1}$; Cu: $28,18 \mathrm{mg} \mathrm{kg}^{-1}$; Fe: 6.110,38 mg kg-1; Mn: 84,22 $\mathrm{mg} \mathrm{kg}^{-1}$; Pb: 25,71 $\mathrm{mg} \mathrm{kg}^{-1}$, e Zn: $38,05 \mathrm{mg} \mathrm{kg}^{-1}$. 
Tabela 1. Características químicas e físicas do solo (Planossolo Háplico) nas diferentes profundidades antes da instalação do experimento

\begin{tabular}{|c|c|c|c|c|c|c|c|c|c|c|}
\hline \multirow{2}{*}{ Profundidade } & \multirow{2}{*}{$\mathrm{pH}\left(\mathrm{H}_{2} \mathrm{O}\right)$} & \multirow{2}{*}{ Corg. } & \multirow{2}{*}{ Norg. } & \multicolumn{2}{|c|}{ Nmineral } & \multirow{2}{*}{ Areia } & \multirow{2}{*}{ Silte } & \multirow{2}{*}{ Argila } & \multirow{2}{*}{ Silte/argila } & \multirow{2}{*}{$\mathrm{GF}^{*}$} \\
\hline & & & & $\mathrm{NH}_{4}$ & $\mathrm{NO}_{3}$ & & & & & \\
\hline $\mathrm{cm}$ & $1: 2,5$ & $\mathrm{~g}$ & -1 & $\mathrm{n}$ & $g^{-1}$ & 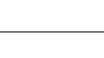 & $\mathrm{g} \mathrm{kg}^{-1}$ & & & $\%$ \\
\hline 0 a 10 & 5,4 & 14,8 & 1,75 & 9,82 & 8,91 & 628 & 115 & 257 & 2,2 & 32,7 \\
\hline 10 a 20 & 5,4 & 11,3 & 1,52 & 8,27 & 8,32 & 590 & 109 & 301 & 2,8 & 29,1 \\
\hline 20 a 30 & 5,2 & 8,0 & 1,12 & 7,64 & 6,47 & 560 & 120 & 320 & 2,7 & 15,3 \\
\hline 30 a 60 & 5,0 & 6,0 & 0,83 & 5,02 & 5,54 & 501 & 105 & 394 & 3,8 & 16,4 \\
\hline 60 a 90 & 5,0 & 5,0 & 0,59 & 4,40 & 3,98 & 433 & 100 & 467 & 4,7 & 17,3 \\
\hline
\end{tabular}

* Grau de floculação

As concentrações dos elementos $\mathrm{Cd}, \mathrm{Cu}, \mathrm{Pb}$ e Zn estiveram abaixo dos limites máximos permitidos pela resolução n. ${ }^{\circ} 375$ do Conselho Nacional de Meio Ambiente - CONAMA (2006), que regula o uso de biossólidos em áreas agrícolas no Brasil. Os teores de $\mathrm{Ca}, \mathrm{Mg}, \mathrm{P}, \mathrm{K}, \mathrm{Cd}, \mathrm{Cu}, \mathrm{Fe}, \mathrm{Mn}, \mathrm{Pb}$ e $\mathrm{Zn}$, no resíduo foram determinados a partir da digestão nitroperclórica, na proporção de 6:1, pelo método de TEDEsCo et al. (1995).

Foram testadas as doses equivalentes a 25, 50 e $100 \mathrm{Mg} \mathrm{ha}^{-1}$ de lodo. O delineamento experimental foi em blocos ao acaso, com quatro tratamentos e três repetições, totalizando 12 parcelas experimentais. A área útil de cada parcela compreendeu $16 \mathrm{~m}^{2}$. O fator doses do LETRIP compõe a parcela e o fator tempo de coleta a subparcela, no caso das variáveis avaliadas no tempo. Antes da aplicação do resíduo, o solo foi submetido a uma aração e duas gradagens (3 e 4/10/ 2004), utilizando a grade aradora pesada.

A aplicação das doses equivalentes a $0 ; 25 ; 50$ e $100 \mathrm{Mg} \mathrm{ha}^{-1}$ de LETRIP foi realizada no período de 15 de novembro a 17 de dezembro de 2004, com a umidade original (78\%). No entanto, adotou-se o fator de correção para obtenção da dose correspondente à sua matéria seca. Para uniformizar a distribuição do produto foi realizada, adicionalmente, a incorporação com enxada rotativa. Cada parcela foi dividida ao meio, sendo metade da parcela cultivada com soja (cv. Celeste), e metade mantida livre de plantas para o monitoramento da dinâmica N-mineral do solo.

A semeadura da soja foi realizada no período de 13 a 20/1/2005, aproximadamente 40 dias após a aplicação do resíduo. $\mathrm{O}$ espaçamento entre linhas foi de $40 \mathrm{~cm}$ e a densidade de plantas foi de 20 por metro linear para evitar a ocorrência de plantas daninhas. A área útil de cada parcela foi representada pelas três fileiras centrais, descartando-se $1 \mathrm{~m}$ das extremidades de cada fileira. As sementes foram submetidas à inoculação com Bradyrizobium japonicum, estirpes BR 29 e BR 96, recomendadas para a cultura da soja. Foi realizada apenas uma adubação suplementar com fósforo equivalente a $60 \mathrm{~kg} \mathrm{ha}^{-1}$ de $\mathrm{P}_{2} \mathrm{O}_{5}$, aplicando-se $400 \mathrm{~kg} \mathrm{ha}^{-1} \mathrm{de}$ Termofosfato Yoorin no momento da semeadura.

O solo foi amostrado aos 30, 60, 120 e 180 dias após a aplicação dos resíduos para determinação do C-orgânico, e aos 30, 60 e 120 dias para o N-mineral e aos 30 e 120 dias para o N-total. Coletaram-se quatro amostras simples de solo de cada parcela experimental e de cada profundidade, e misturou-se para formar uma amostra composta, nas profundidades de 0-10, 10-20, 20-40, 40-60 e 60 a $90 \mathrm{~cm}$. As amostras foram secas ao ar, destorroadas, homogeneizadas e passadas através de uma peneira de $2 \mathrm{~mm}$ de malha. Os teores de carbono orgânico (CO) foram determinados pelo método proposto pela EMBRAPA (1997). Os teores de N-total foram obtidos mediante digestão sulfúrica e o extrato analisado pelo método Kjeldahl. A determinação dos teores de $\mathrm{N}-\mathrm{NH}_{4}^{+}$ e N-NO $\mathrm{NO}_{3}^{-}+\mathrm{N}-\mathrm{NO}_{2}^{-}$foi feita a partir da extração com $\mathrm{KCl}$ $2 \mathrm{~mol} \mathrm{~L}^{-1}$, seguida de destilação em meio alcalino com $\mathrm{MgO}$ e liga de Devarda (TEDEsco et al., 1995). Com base nestas determinações foram estimados, por diferença, os teores de N-orgânico. Essas análises foram realizadas nos laboratórios do Departamento de Solos da UFRRJ.

Para avaliação da massa seca e nodulação foram retiradas cinco plantas de cada parcela aos 55 dias após a emergência (DAE) das plântulas, correspondendo aos estádios de pré-florescimento e formação de vagens. $\mathrm{O}$ sistema radicular foi lavado e contados os nódulos viáveis (nódulo de aparência normal com a presença da leghemoglobina, conferida pela cor avermelhada); podres (cor marrom-clara ou verde, com superfície externa rugosa e consistência mais mole) e verdes (nódulo de aparência normal, mas seu interior é branco esverdeado, ou apenas um pouco rosado), adaptado de RAVEN et al. (2001), os quais foram levados à estufa de ventilação forçada a 65 ${ }^{\circ} \mathrm{C}$ até massa constante. 
As cinco plantas utilizadas (por parcela) na avaliação da massa acumulada da parte aérea foram secas, moídas e analisadas para a determinação do teor de nitrogênio, por digestão sulfúrica e destilação a vapor (TeDEsco et al., 1995). A produtividade de grãos da cultivar de soja Celeste foi determinada a partir da colheita de $2,4 \mathrm{~m}^{2}$ da área útil de cada parcela. A produção obtida foi transformada em $\mathrm{Mg} \mathrm{ha}^{-1}$ de grãos a $13 \%$ de umidade.

Os resultados de $\mathrm{C}$ e $\mathrm{N}$ total, $\mathrm{N}$-orgânico, $\mathrm{N}-\mathrm{NH}_{4}{ }^{+}$ e a soma de $\mathrm{N}-\mathrm{NO}_{3}{ }^{-}$com $\mathrm{N}-\mathrm{NO}_{2}{ }^{-}$, em cada profundidade, foram comparados por meio do erro-padrão da média. Os resultados de matéria seca, produção de grãos, número de nódulos e acúmulo de $\mathrm{N}$ na planta foram submetidos à análise de variância. Quando apropriado, foram ajustadas equações, escolhendo-se a significativa de maior coeficiente de determinação.

\section{RESULTADOS E DISCUSSÃO}

Os teores de carbono orgânico nas diferentes camadas do solo indicam efeito altamente significativo para a interação entre doses de LETRIP e a época de coleta $(\mathrm{p} \leq 0,013)$, exceto para a profundidade de $10-20 \mathrm{~cm}$, onde ocorreu o maior coeficiente de variação (Tabela 2). Os teores de carbono orgânico foram mais elevados, principalmente, na camada superficial $(0-10 \mathrm{~cm})$, com teores 1,5 vezes maiores que a testemunha na maior dose do resíduo LETRIP, com reduções dos teores em profundidade para todos os tratamentos (Figura 1).

O acúmulo de carbono orgânico na camada mais superficial $(0-10 \mathrm{~cm})$ foi seguido de uma transição abrupta para as camadas de $10-20$ e $20-$ $40 \mathrm{~cm}$ e, mais suavemente, para as de $40-60 \mathrm{~cm}$ e $60-$ $90 \mathrm{~cm}$. BORGES e COUTINHO (2004) observaram aumentos lineares dos teores de matéria orgânica em Neossolo Quartzarênico órtico típico e Latossolo Vermelho eutroférrico argiloso, devido ao carbono orgânico presente no biossólido aplicado em ambos os solos. O maior teor de C-orgânico na camada superficial do solo estudado, em relação às camadas inferiores, devese ao fato de o LETRIP ter sido incorporado na camada de 0 a $20 \mathrm{~cm}$. Comportamento semelhante foi observado por GONÇALVES e CERETTA (1999), os quais verificaram que a distribuição em profundidade dependeu, principalmente, do modo pelo qual se incorporou o resíduo no solo. Nos diferentes sistemas de preparo do solo e tipos de rotação de culturas, avaliados por Silveira e STONe (2001), também se notaram um decréscimo do teor de carbono em profundidade. Esses autores observaram ainda que o contato entre os resíduos e o solo variava, principalmente, em função do tamanho das partículas dos resíduos e da sua localização, e da forma de incorporação no solo (superfície ou incorporados).

Os maiores valores de $\mathrm{N}$-orgânico foram observados na maior dose de LETRIP (Figura 2). Não houve diferença significativa nos teores entre as épocas de coleta na camada superficial do solo (Tabela 2), entretanto, a partir da profundidade de $30 \mathrm{~cm}$, houve efeito significativo da época de coleta $(p<0,04)$, com valores mais elevados aos 30 dias e menores aos 120 dias após a incorporação, indicando, possivelmente, que ocorreu a mineralização do $\mathrm{N}$ orgânico. InMAN et al. (1982) verificaram que doses de 150 e $300 \mathrm{Mg} \mathrm{ha}^{-1}$ (base seca) de um composto a base de lodo de esgoto proporcionaram, após 30 meses da sua aplicação, aumentos de duas a três vezes nos teores de $\mathrm{N}$ orgânico na camada de $0-15 \mathrm{~cm}$ do solo quando comparado à testemunha.

A aplicação de doses crescentes do LETRIP proporcionou também aumento nas concentrações de $\mathrm{N}$-mineral (Figura 2), sendo os teores de $\mathrm{N}-\mathrm{NH}_{4}^{+}$e N$\mathrm{NO}_{3}^{-}$semelhantes. A alternância de períodos de intensa precipitação pluvial com a saturação da umidade do solo e períodos secos, durante o ciclo da soja, pode justificar o equilíbrio entre as duas frações de $\mathrm{N}$-mineral $\left(\mathrm{N}-\mathrm{NH}_{4}^{+}\right.$e N-NO $\mathrm{NO}_{3}^{-}$) neste experimento. Houve maior concentração de $\mathrm{N}-\mathrm{NH}_{4}^{+}$e $\mathrm{N}-\mathrm{NO}_{3}^{-}$em superfície e redução em profundidade, para todos os tratamentos. Para a testemunha as diferenças de concentração em função da variação de profundidade são menores.

Os teores de $\mathrm{N}$-mineral foram maiores na maior dose do LETRIP, sendo a média dos teores de $\mathrm{N}-\mathrm{NH}_{4}^{+} \mathrm{e}-\mathrm{NO}_{3}^{-}$de 18,7 e $18,6 \mathrm{mg} \mathrm{kg}^{-1}$, correspondendo a um incremento de $87 \%$ e $104 \%$, respectivamente, comparado à testemunha $\left(10,0\right.$ e $9,1 \mathrm{mg} \mathrm{kg}^{-1}$ de $\mathrm{N}_{-} \mathrm{NH}_{4}^{+}$ e $\mathrm{N}-\mathrm{NO}_{3}^{-}$) nos primeiros $10 \mathrm{~cm}$ de profundidade. A partir dos $20 \mathrm{~cm}$ de profundidade esta diferença diminuiu consideravelmente (Figura 2). Novamente, há de se destacar a influência da localização e forma de incorporação do LETRIP no solo que, provavelmente, favoreceu o aumento da taxa de mineralização do N-orgânico e, consequentemente, os teores de N-mineral. E possível que o N-NH$H_{4}^{+}$tenha sido oxidado a $\mathrm{N}^{-\mathrm{NO}_{3}^{-}}$e, não sendo absorvido pelas plantas ou imobilizado na biomassa microbiana, pode ter sido perdido por lixiviação no perfil do solo, com a possibilidade de contaminação de água subterrânea.

Logo após a adição de biossólido ao solo ocorre um intenso processo de mineralização do N-orgânico, bem como perdas por volatilização do $\mathrm{N}-\mathrm{NH}_{4}^{+}$(VIEIRA e CARdoso, 2003). Como as avaliações no solo neste experimento somente tiveram início aos 30 dias após a aplicação dos resíduos, as transformações iniciais de N, neste solo, não foram observadas. De forma geral, a maior mineralização ocorreu aos 60 dias após aplicação dos resíduos (Figura 2). 
Tabela 2. Valores de $\mathrm{F}\left({ }^{1}\right)$ para carbono, N-orgânico, $\mathrm{N}-\mathrm{NH}_{4}^{+}$e $\mathrm{N}-\mathrm{NO}_{3}^{-}$nas diferentes profundidades do solo em função das doses de LETRIP e da época de coleta

\begin{tabular}{|c|c|c|c|c|}
\hline \multirow{2}{*}{ Fontes de variação } & \multicolumn{4}{|c|}{ Variáveis } \\
\hline & Carbono & N-orgânico & $\mathrm{NH}_{4}^{+}$ & $\mathrm{NO}_{3}^{-}$ \\
\hline & & $\mathrm{g} \mathrm{kg}^{-1}$ & $\mathrm{mg} \mathrm{kg}^{-1}$ & $\mathrm{mg} \mathrm{kg}^{-1}$ \\
\hline LETRIP (L) & $72,81(0,000)$ & $19,36(0,002)$ & $2,44(0,163)$ & $4,08(0,067)$ \\
\hline Coleta (C) & $15,95(0,000)$ & $0,05(0,822)$ & $3,29(0,064)$ & $4,94(0,021)$ \\
\hline $\mathrm{L}^{*} \mathrm{C}$ & $3,97(0,013)$ & $0,13(0,941)$ & $0,53(0,775)$ & $1,62(0,206)$ \\
\hline CV1 (\%) & 5,77 & 7,50 & 49,85 & 43,20 \\
\hline CV2 (\%) & 10,13 & 15,76 & 71,95 & 31,07 \\
\hline LETRIP (L) & $0,46(0,718)$ & $3,29(0,100)$ & $4,23(0,063)$ & $1,27(0,365)$ \\
\hline Coleta (C) & $2,07(0,158)$ & $0,10(0,761)$ & $4,23(0,033)$ & $6,45(0,009)$ \\
\hline $\mathrm{L}^{*} \mathrm{C}$ & $0,57(0,752)$ & $0,10(0,959)$ & $1,63(0,202)$ & $1,17(0,369)$ \\
\hline CV1 (\%) & 37,79 & 14,56 & 46,47 & 38,34 \\
\hline CV2 (\%) & 24,14 & 19,96 & 56,62 & 35,03 \\
\hline LETRIP (L) & $58,66(0,000)$ & $0,31(0,818)$ & $4,47(0,057)$ & $4,96(0,046)$ \\
\hline Coleta (C) & $13,27(0,000)$ & $8,99(0,017)$ & $2,08(0,157)$ & $7,95(0,004)$ \\
\hline${ }^{*} \mathrm{C}$ & $15,24(0,000)$ & $1,52(0,282)$ & $0,90(0,519)$ & $0,62(0,712)$ \\
\hline CV1 (\%) & 5,69 & 23,28 & 37,05 & 27,73 \\
\hline CV2 (\%) & 7,64 & 22,26 & 45,57 & 51,36 \\
\hline LETRIP (L) & $1,22(0,381)$ & $1,03(0,443)$ & $7,01(0,022)$ & $1,92(0,228)$ \\
\hline Coleta (C) & $1,78(0,201)$ & $6,90(0,030)$ & $2,01(0,166)$ & $12,04(0,001)$ \\
\hline $\mathrm{L}^{*} \mathrm{C}$ & $4,34(0,009)$ & $0,29(0,832)$ & $2,41(0,075)$ & $0,35(0,900)$ \\
\hline CV1 (\%) & 14,81 & 28,45 & 30,33 & 44,85 \\
\hline CV2 (\%) & 12,62 & 34,87 & 33,54 & 50,01 \\
\hline LETRIP (L) & $51,71(0,000)$ & $0,34(0,795)$ & $6,02(0,031)$ & $1,47(0,315)$ \\
\hline Coleta (C) & $1,07(0,365)$ & $6,08(0,039)$ & $2,22(0,142)$ & $6,39(0,009)$ \\
\hline $\mathrm{L}^{*} \mathrm{C}$ & $15,18(0,000)$ & $0,06(0,978)$ & $5,77(0,002)$ & $0,08(0,998)$ \\
\hline CV1 (\%) & 4,76 & 37,66 & 32,99 & 62,10 \\
\hline CV2 (\%) & 8,85 & 66,08 & 30,57 & 82,60 \\
\hline
\end{tabular}

$\left({ }^{1}\right)$ Valor entre parêntese refere-se a significância do F (p). CV1 é coeficiente de variação da parcela (LETRIP) e CV2 da subparcela (época de coleta).

$\mathrm{O}$ aumento dos teores de N-mineral, em profundidade, após a aplicação de biossólidos tem sido, freqüentemente, encontrado na literatura, o que é indicativo de lixiviação (Molina et al., 2006). No presente trabalho, não ocorreu acúmulo de $\mathrm{N}-\mathrm{NO}_{3}^{-}$, mas houve acúmulo de $\mathrm{N}-\mathrm{NH}_{4}^{+}$. Este acúmulo pode estar relacionado às intensas precipitações pluviais que ocorreram durante o período de realização do experimento e pela condição de encharcamento da área de estudo, onde há uma drenagem impedida. Em solos saturados ocorre acúmulo de $\mathrm{N}-\mathrm{NH}_{4}^{+}$, pois a ausência de oxigênio interrompe a nitrificação do nitrogênio na forma amoniacal. O N-NO${ }_{3}^{-}$é rapidamente reduzido a $\mathrm{N}_{2} \mathrm{O}$ e $\mathrm{N}_{2}$ voláteis, desaparecendo do solo em poucos dias de saturação (SousA et al., 2004). 


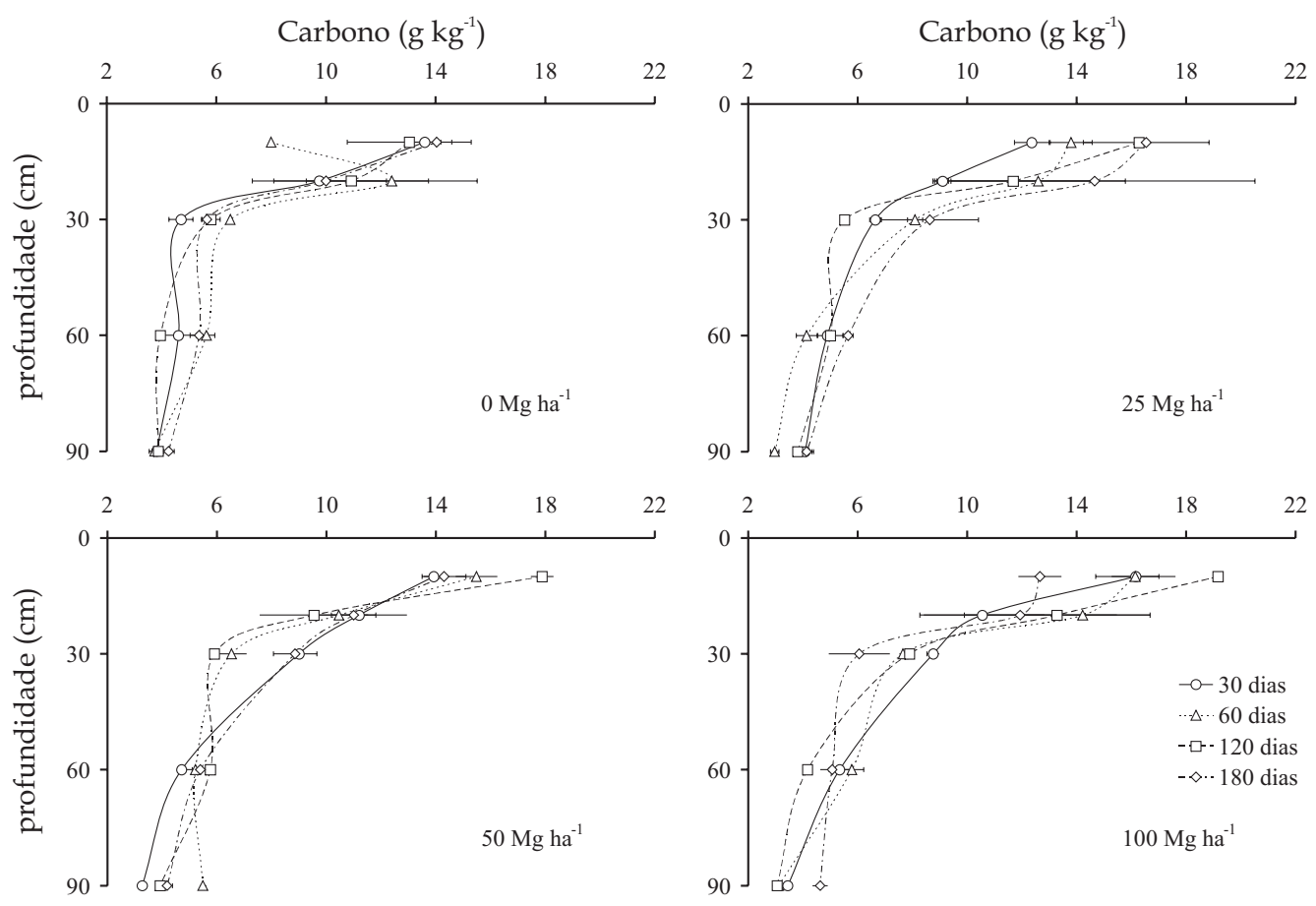

Figura 1. Distribuição dos teores de carbono orgânico em profundidade, em função das doses de LETRIP e da época de coleta. Barras horizontais em cada ponto representam o erro-padrão da média.

A perda inicial ocorre logo após a saturação do solo, quando o $\mathrm{N}-\mathrm{NO}_{3}^{-}$, mineralizado durante o período aeróbio, é desnitrificado a $\mathrm{N}_{2} \mathrm{O}$ e $\mathrm{N}_{2}$. $\mathrm{O}$ N-NH $\mathrm{NH}_{4}^{+}$ formado pela mineralização da matéria orgânica é estável na zona reduzida do solo. No entanto, o $\mathrm{N}-\mathrm{NH}_{4}^{+}$pode ser nitrificado e, posteriormente, difundir-se para as zonas reduzidas e ser desnitrificado pelos microorganismos anaeróbios a $\mathrm{N}_{2} \mathrm{O}$ e $\mathrm{N}_{2}$ (SousA et al., 2004).

Outra possibilidade do predomínio de $\mathrm{N}-\mathrm{NH}_{4}^{+}$ em profundidade, em relação ao $\mathrm{N}^{-\mathrm{NO}_{3}^{-}}$, é que o $\mathrm{N}-\mathrm{NO}_{3}^{-}$tenha se acumulado em uma camada abaixo da avaliada neste experimento. Estudos recentes comprovam que mesmo nos Latossolos com balanço de carga positiva na superfície pode ocorrer perdas expressivas de $\mathrm{N}^{-\mathrm{NO}_{3}^{-}}$por lixiviação (DYNIA, 2000). Esse autor observou que $\mathrm{N}-\mathrm{NO}_{3}^{-}$movimentava-se além da zona de exploração radicular da maioria das culturas, alcançando profundidades de 2 a $6 \mathrm{~m}$ e acumulando-se nessa profundidade. Perdas maiores que $100 \mathrm{~kg} \mathrm{ha}^{-1} \mathrm{ano}^{-1}$ de foram observadas em solos que receberam lodo de esgoto, ou mesmo adubação nitrogenada convencional, para a cultura da cana-de-açúcar (Oliveira et al., 2001).

A aplicação no solo de doses de lodo de esgoto, a partir de $33 \mathrm{Mg} \mathrm{ha}^{-1}$ ocasionou riscos de poluição das águas subterrâneas com nitrato, demonstrando que o nitrogênio deve ser considerado como fator restritivo quando da definição das taxas anuais e freqüência de aplicação de resíduos orgânicos (Oliveira et al., 2001). As quantidades de lodo de esgoto a serem aplicadas ao solo devem ser diferentes no período da seca e das águas, mesmo quando se baseiam nas necessidades de $\mathrm{N}$ em decorrência das perdas desse elemento em períodos de intensa precipitação (VIEIRA e CARDOSO, 2003). A Norma n. ${ }^{\circ} 375$ do ConAma (2006) prevê na definição da taxa anual de aplicação de lodo que a quantidade de $\mathrm{N}$ mineralizado não poderá ser superior ao demandado por uma cultura agrícola.

Na tabela 3 observa-se efeito das doses de LETRIP altamente significativo para massa seca total e de caule ( $\mathrm{p} \leq 0,001)$ e significativo para massa seca de raízes $(p<0,03)$ e folhas $(p<0,07)$. Em todos os tratamentos houve boa acumulação de biomassa total (de 2 a $4 \mathrm{Mg} \mathrm{ha}^{-1}$ ) (Figura 3), considerando o curto período correspondente à emergência das plântulas e sua coleta ( 55 dias). No entanto, este acúmulo foi inferior aos valores observados por PADOVAN (2002), de $8,33 \mathrm{Mg} \mathrm{ha}^{-1}$. Ocorre um aumento na produção de massa seca total acumulada com as doses do LETRIP, exceto para a dose de $25 \mathrm{Mg} \mathrm{ha}^{-1}$ de LETRIP onde se verificou redução da massa seca em relação à testemunha (Figura 3).

Analisando-se o número total de nódulos por planta observa-se efeito significativo $(p \leq 0,035)$, através da análise de variância, para o efeito das doses do LETRIP, não ocorrendo diferenças para o número de 
nódulos viáveis (Tabela 3). O número de nódulos verdes teve efeito significativo ( $\mathrm{p} \leq 0,033)$, no entanto, nenhum dos modelos de regressão testados ajustou-se aos dados. Com relação ao número de nódulos podres houve efeito altamente significativo do LETRIP $(p<0,001)$, aumentando o número de nódulos podres com o aumento da dose LETRIP, ou seja, pode estar afetando de forma negativa a fixação biológica de nitrogênio.

Para a massa seca de nódulos não houve efeito das doses de LETRIP, obtendo-se a massa seca média de $326,06 \mathrm{mg}$ por planta (dados não apresentados). Aos 55 dias após a emergência, na cultivar Celeste notou-se grande número de nódulos por planta, valores superiores aos verificados por PADOVAN (2002). Uma planta de soja bem nodulada deve mostrar no campo, no estádio de florescimento, entre 15 e 30 nódulos por planta ou 100 e $200 \mathrm{mg}$ de massa nodular por planta (VARGAS et al., 1982).
Considerando-se apenas o número total de nódulos, em todos os tratamentos constatou-se um número de nódulos por planta superior a vinte.

No entanto, quando se analisa o número de nódulos viáveis, observa-se que em $75 \%$ dos tratamentos, havia menos de 15 nódulos viáveis por planta. Giller et al. (1989) atestaram que somente populações ineficientes de Rizobium leguminosarum bv. trifolii sobreviveram em solo 50 anos após aplicação de lodo. Esses autores observaram redução significativa na fixação biológica do $\mathrm{N}_{2}$, quando comparado ao tratamento controle, isto é, sem adição de lodo de esgoto. HabD-Alla et al. (1999) demonstraram que a aplicação de lodo de esgoto à cultura da soja pode aumentar tanto a fixação do nitrogênio quanto a sua nodulação.
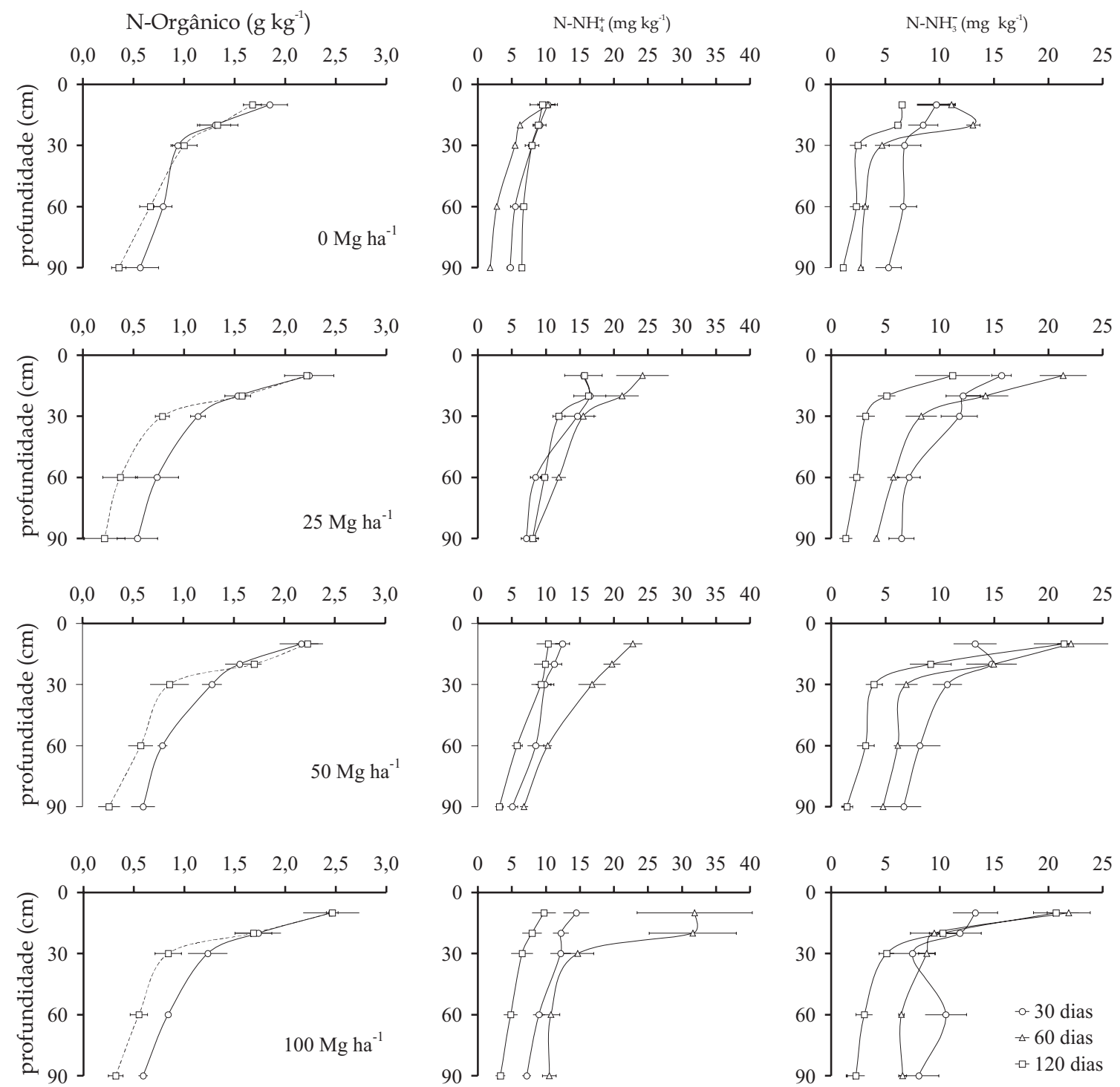

Figura 1. Distribuição dos teores de N-orgânico, $\mathrm{N}-\mathrm{NH}_{4}^{+}$e N-NO $3-$ em função das doses de LETRIP e da época de coleta. Barras horizontais em cada ponto representam o erro-padrão. 
Tabela 3. Valores de F, significância (p) e coeficiente de variação $(\mathrm{CV})$ para número de nódulos (total, viáveis, verdes e podres), massa seca das plantas (total, caule, folhas e raízes), N-total (raízes, caule, folhas e grãos) e produtividade da cultivar de soja Celeste em função de doses do LETRIP

\begin{tabular}{lccc}
\hline Variáveis & $\mathrm{F}$ & $\mathrm{p}$ & $\mathrm{CV}(\%)$ \\
\hline Número de nódulos & & & \\
Total & 5,68 & 0,035 & 21,05 \\
Viáveis & 1,80 & 0,248 & 57,25 \\
Verdes & 5,81 & 0,033 & 42,20 \\
Podres & 59,55 & 0,000 & 14,53 \\
Massa seca $\left(\mathrm{Mg} \mathrm{ha}^{-1}\right)$ & & & \\
Total & 66,31 & 0,000 & 5,80 \\
Caule & 23,74 & 0,001 & 11,69 \\
Folhas & 4,04 & 0,069 & 20,26 \\
Raízes & 6,72 & 0,024 & 16,4 \\
N-total (g kg-1) & & & \\
Raízes & 9,58 & 0,011 & 7,26 \\
Caule & 1,01 & 0,453 & 5,27 \\
Folhas & 6,34 & 0,027 & 8,72 \\
Grãos & 1,95 & 0,222 & 5,56 \\
Produtividade (Mg ha $\left.{ }^{-1}\right)$ & 27,14 & 0,001 & 5,40 \\
\hline
\end{tabular}

A alta nodulação alcançada pela cultivar Celeste indicou bom desempenho em relação à nodulação, no entanto, com o aumento das doses do LETRIP, sua eficiência pode ter sido reduzida consideravelmente, devido ao aumento do número de nódulos podres e diminuição do número de nódulos verdes (Figura 3).

A elevada oferta de N-mineral (Figura 2) para as plantas de soja acarretou, provavelmente, alta absorção de N-mineral do solo, implicando, possivelmente, redução da FBN. Em condições de alta disponibilidade de $\mathrm{N}$-mineral, as plantas não nodulam ou reduzem a fixação nos nódulos. A nitrogenase, enzima catalisadora da fixação do nitrogênio utiliza grandes quantidades de ATP como fonte de energia, tornando a fixação de nitrogênio um processo metabólico oneroso, daí a preferência da planta por vias de menor custo energético (RAVEN et al., 2001).

A paralisação da atividade fixadora inicia o processo de degeneração e seu início depende também de muitos fatores como: toxidez, deficiência em determinados elementos essenciais; condições de umidade; ataque de parasitas, etc. A alta correlação positiva observada entre os teores de $\mathrm{N}$ no solo e o número de nódulos podres por planta $(\mathrm{r}=0,99)$ corrobora com essa hipótese.
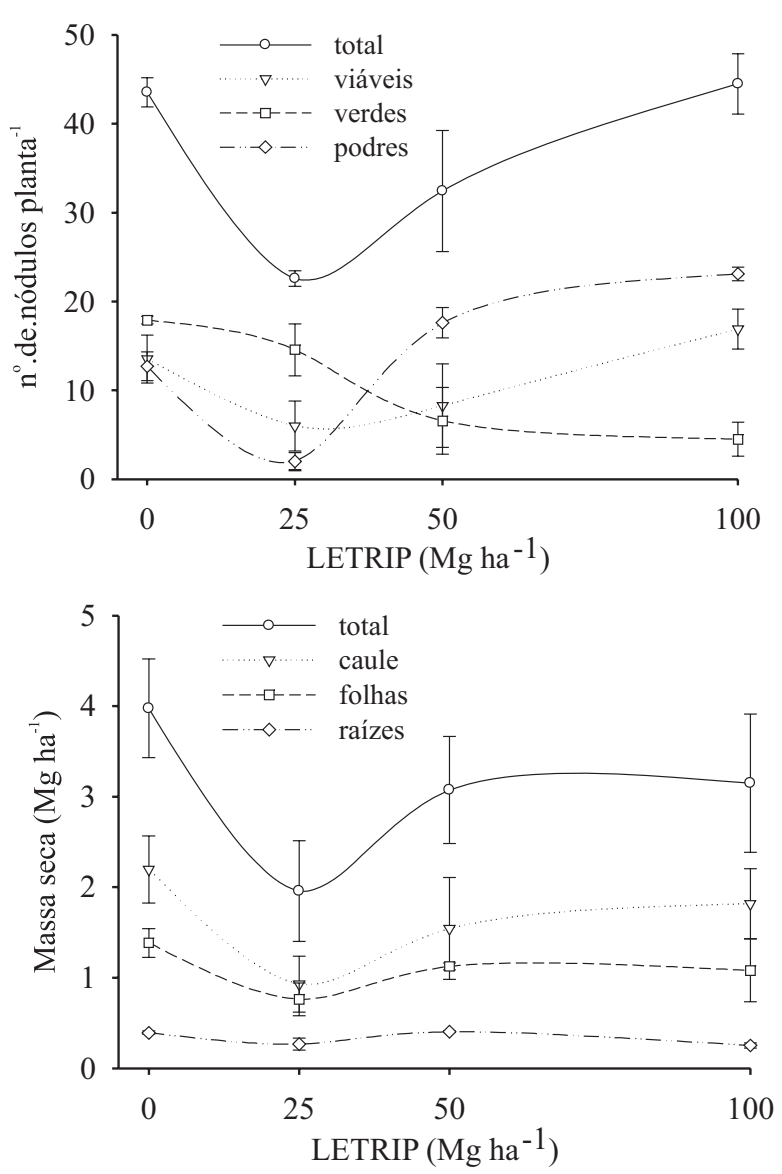

Figura 3. Produção de massa seca acumulada (total, raízes, caule e folhas) e número de nódulos (total, viáveis, verde e podres) da cultivar de soja Celeste aos 55 dias após a emergência, submetida às diferentes doses do LETRIP. Barras verticais em cada ponto representam o erro-padrão da média.

O nitrogênio é o nutriente que a soja mais absorve depois do $\mathrm{C}, \mathrm{O}$ e $\mathrm{H}$, acumulando-se nos grãos na faixa de 5-6\%, o que corresponde a $150-180 \mathrm{~kg} \mathrm{ha}^{-1}$ de $\mathrm{N}$, para a produtividade média de $3 \mathrm{Mg} \mathrm{ha}^{-1}$ (Alvez et al., 2000).

O teor de $\mathrm{N}$ total no caule e nos grãos de soja não revelou efeito significativo na análise de variância para o efeito das doses de LETRIP (Tabela 3). Em média os teores de $\mathrm{N}$ foram maiores nos grãos do que nas folhas, caule e raízes, corroborando com BATAGLiA et al. (1981). Segundo esses autores, os teores de macronutrientes em geral, são maiores na parte reprodutiva (vagens mais sementes), quando se compara com a parte vegetativa. Foram também observados efeitos significativos $(p<0,05)$ para o teor de $N$ total nas folhas e raízes com resposta linear às doses de LETRIP (Figura 4). 

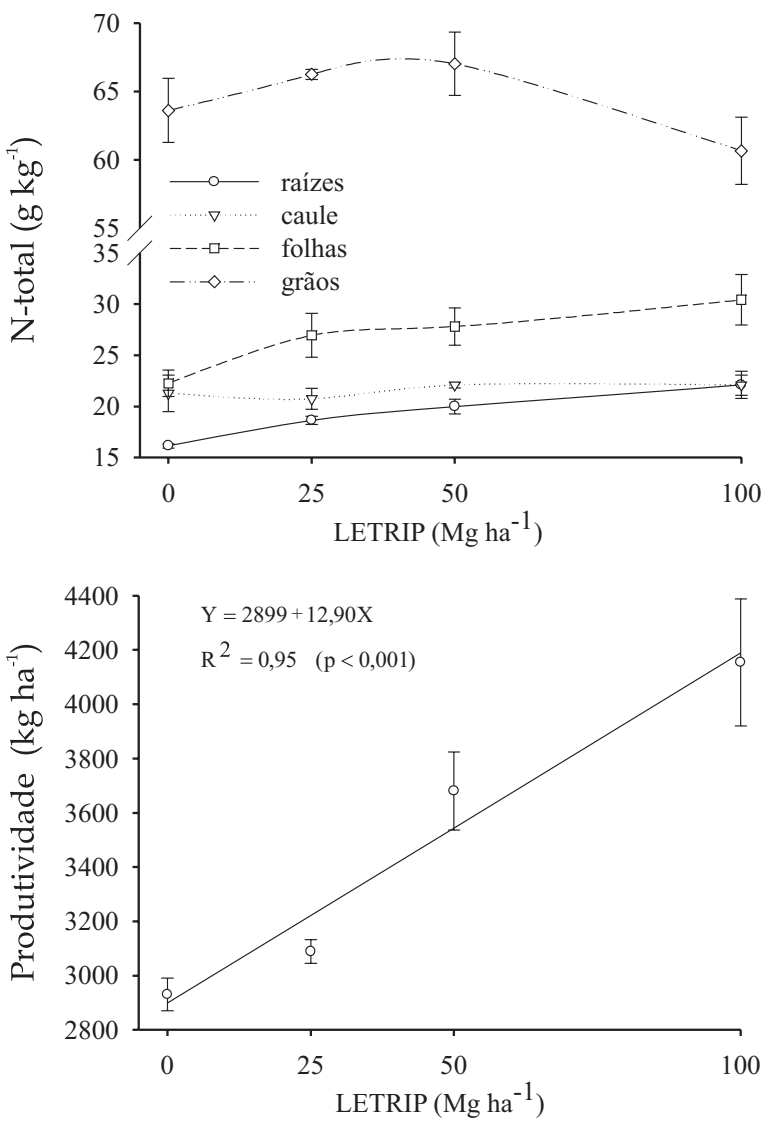

Figura 4. Teor de nitrogênio total e produtividade de grãos da cultivar de soja Celeste, em função de diferentes doses do LETRIP. Barras verticais em cada ponto representam o erro-padrão da média.

Na análise de variância para produtividade $\left(\mathrm{kg} \mathrm{ha}^{-1}\right)$ foi observado efeito altamente significativo para o fator doses de LETRIP ( $p<0,001$, Tabela 3 ). Considerando-se os valores médios estimados para a produtividade de grãos, no modelo que melhor se ajustou aos dados notou-se efeito linear, obtendo coeficiente de determinação $\left(R^{2}\right)$ de 0,95 (Figura 4). A aplicação do LETRIP acarretou incremento de produtividade superior a $1.224 \mathrm{~kg} \mathrm{ha}^{-1}$ em relação à testemunha. VIEIRA et al. (2004), utilizando lodo de esgoto, como fonte de $\mathrm{P}$, na fixação de $\mathrm{N}_{2}$, e na produção da soja, observaram que, em média, os tratamentos que continham lodo produziram cerca de $160 \mathrm{~kg} \mathrm{ha}^{-1}$ de grãos a mais que no tratamento com adubação química completa no primeiro ano de cultivo. No segundo ano, a produção foi, em média, $403 \mathrm{~kg} \mathrm{ha}^{-1}$ de grãos a mais que no tratamento testemunha.

O efeito do LETRIP na produtividade pode ser explicado em razão deste proporcionar melhores condições para as propriedades químicas e físicas do solo ao longo do perfil, induzindo assim, maior exploração radicular. Outro aspecto a se levar em consideração diz respeito à área de estudo, que estava por longo período em pousio, aproximadamente dez anos, ou seja, em bom estado de manutenção dos teores de matéria orgânica e nutrientes, visto que se obteve através da testemunha produtividade superior a $2.900 \mathrm{~kg} \mathrm{ha}^{-1}$, produtividade maior que a média nacional (CONAB, 2005; Embrapa Soja, 2005). Embora, sob estas condições, o resíduo melhorou o potencial produtivo da área, o que indica maior potencial quando utilizado em áreas empobrecidas e/ou degradadas através de sua exploração intensa, ou seja, pode se observar uma magnitude de resposta superior às obtidas nas condições deste experimento.

\section{CONCLUSÕES}

1. Os teores de carbono e nitrogênio orgânico no solo aumentaram com a aplicação do LETRIP.

2. Em todas as camadas do solo, foram observados aumentos nos teores de $\mathrm{N}$-mineral em função da aplicação do LETRIP.

3. A aplicação de doses crescentes do LETRIP aumentou a disponibilidade de $\mathrm{N}$ às plantas de Glycine max (L.) Merr., cv. Celeste; durante seu ciclo, exceto nos grãos.

4. Ocorreu uma redução no número total de nódulos por planta nas doses de 25 e $50 \mathrm{Mg} \mathrm{ha}^{-1}$ do LETRIP.

5. As doses crescentes do LETRIP propiciaram incrementos de até $1224 \mathrm{~kg} \mathrm{ha}^{-1}$ na produtividade de soja, comparada à testemunha, melhorando o potencial produtivo da área.

\section{REFERÊNCIAS}

ALLOS, H. F.; BARTHOLOMEU, W. W. Replacement of symbiotic fixation by available nitrogen. Soil Science, Madison, v.87, p.61-66, 1959.

ALVES, B. J. R.; ZOTARELLI, L.; BODDEY. R. M.; URQUIAGA. S. S. C. Transformação do nitrogênio em rotações de culturas sob sistemas plantio direto. In: WORKSHOP SOBRE NITROGÊNIO NA SUSTENTABILIDADE DE SISTEMAS INTENSIVOS DE PRODUÇÃO AGROPECUÁRIA, 2000, Dourados. Anais... Dourados: Embrapa Agropecuária Oeste; 2000. p. 9-31. (Embrapa Agropecuária Oeste. Documentos, 26)

ASSOCIAÇÃO BRASILEIRA DE NORMAS TÉCNICAS. NBR-10007: Amostragem de resíduos. Rio de Janeiro, 2004. 21p.

BATAGLIA, O. C.; MASCARENHAS, H. A. A.; MIYASAKA, S. Extração e níveis de nutrientes. In: MIYASAKA, S.; MEDINA, J. C. A soja no Brasil. Campinas: Instituto de Tecnologia de Alimentos, 1981. p.156-167. 
BERGAMASCO, A. F.; SILVA, F. C.; RODRIGUES, L. H. A.; TRIVELIN, P. C. O. Modelo de balanço de nitrogênio para cana-de-açúcar: fase II - construção do modelo no software STELLA. Campinas: Embrapa Informática Agropecuária, 2002. 40p. il. (Boletim de Pesquisa e Desenvolvimento/Embrapa Informática Agropecuária, 8)

BORGES, M. R.; COUTINHO, E. L. M. Metais pesados do solo após aplicação de biossólido. I - Fracionamento. Revista Brasileira de Ciência do Solo, Viçosa, v. 28. p.543-555, 2004.

CONAB. Indicadores da agropecuária. Brasília, 2005. Disponível em:<http://www. conab.gov.br/ > Acesso em: 14 fev. 2005.

CONSELHO NACIONAL DE MEIO AMBIENTE (CONAMA). Resolução n ${ }^{\circ} .375$ de 29 de agosto de 2006. Define critérios e procedimentos para o uso agrícola de lodos de esgoto gerados em estações de tratamento de esgoto sanitário e seus produtos, e da outras providencias. Brasília, 2006.

DYNIA, J. F. Nitrate retention and leaching in variable charge soils of a watershed in São Paulo State, Brazil. Communications in Soil Science and Plant Analysis, Philadelphia. v.31, p.777-791, 2000.

EMPRESA BRASILEIRA DE PESQUISA AGROPECUÁRIA EMBRAPA. Manual de métodos de análises de solos. 2.ed. Rio de Janeiro: EMBRAPA/CNPS, 1997. 214p.

EMPRESA BRASILEIRA DEPESQUISA AGROPECUÁRIA. Centro Nacional de Pesquisa de Soja. Tecnologia de produção de soja Região Central do Brasil - 2005. Londrina: Embrapa Cerrados, Embrapa Agropecuária Oeste, Fundação Meridional, 2005. 239p.

GILLER, K. E.; McGRATH, S. P.; HIRSCH, P. R. Absence of nitrogen fixation in white clover grown on a soil subject to long-term contamination with heavy metals is due to survival of only ineffective rhizobia. Soil Biology and Biochemistry, Oxford, v. 21, p.841-848, 1989.

GONÇALVES, C. N.; CERETTA, C. A. Plantas de cobertura de solo antecedendo o milho e seu efeito sobre o carbono orgânico do solo, sob plantio direto. Revista Brasileira de Ciência do Solo, Viçosa, v.23, p.307- 313, 1999.

HABD-ALLA, M.; YAN, F.; SCHUBERT, S. Effects of sewage sludge application on nodulation, nitrogen fixation, and plant growth of faba bean, soybean and lupin. Journal of Applied Botany, Zeitschrift fuer Angewandte Botanik, Berlin, v.73, p.69-75, 1999.

INMAN, I. C.; McINTOSH, M. S.; FOSS, J. E.; WOLF, D. C. Nitrogen and phosphorus movement in compost-amended soils. Journal of Environmental Quality, Madison, v.11, p.529-532, 1982.

MESQUITA, A. A. Remediação de áreas contaminadas por metais pesados provenientes de lodo de esgoto. 2002. 68p. Dissertação (Mestrado em Agronomia) - Universidade Federal Rural do Rio de Janeiro, Seropédica.

MIRANDA NETO, M. I. Investigação Geoambiental em Área de Mangue na Baía de Guanabara Contaminada com Resíduos Industriais. 2002. 273p. Tese (Mestrado em Engenharia Civil) COOPE, Universidade Federal do Rio de Janeiro, Rio de Janeiro.
MOLINA, M. V.; MATTIAZZO, M. E.; ANDRADE, C. A.; POGGIANI, F. Nitrogênio e metais pesados no solo e em árvores de eucalipto decorrentes da aplicação de biossólido em plantio florestal. Scientia Forestalis, Piracicaba, n.71, p.25-35. 2006.

OLIVEIRA, F. C.; MATTIAZZO, M. E.; C. R.; MORAES, S. O. Lixiviação de nitrato em Latossolo Amarelo distrófico tratado com lodo de esgoto e cultivado com cana-de-açúcar. Scientia Agricola. Piracicaba, v.58, p.171-180. 2001.

PADOVAN, M. P. Desempenho da soja, sob manejo orgânico, para produção de grãos e adubação verde. 2002. 88f. Tese (Doutorado em Agronomia) - Universidade Federal Rural do Rio de Janeiro, Seropédica.

PAUL, E. A.; CLARK, F. E. Soil micro biology and biochemistry. 2.ed. New York: Academic Press, 1996. 340p.

RAVEN, P. H.; EVERT, R. F.; EICHHORN S. E. Biologia de Plantas. 6.ed. Rio de Janeiro: Guanabara Koogan, 2001. p.707-710.

SILVEIRA, P. M.; STONE, L. F. Teores de nutrientes e de matéria orgânica afetados pela rotação de culturas e sistema de preparo do solo. Revista Brasileira de Ciência do Solo, Viçosa. v.25, p.387-394, 2001.

SOUSA, R. O.; CAMARGO, F. A. O.; VAHL, L. C. Solos alagados: reações redox. In: MEURER, E. J. Fundamentos de Química do Solo. 2. ed. Porto Alegre: Genesis, 2004. p.207-236.

TEDESCO, M. J.; GIANELLO, C. A.; BISSANI, C. A.; BOHNEN, H.; VOLKWEISS, S. J. Análise de solo, plantas e outros materiais. 2.ed. Porto Alegre, Universidade Federal do Rio Grande do Sul, 1995. 174p. (Boletim Técnico, n. ${ }^{\circ}$ )

VARGAS, M. A. T.; PERES, J. R. R.; SUHET, A. R. Adubação nitrogenada, inoculação e épocas de calagem para a soja em um solo sob cerrado. Pesquisa Agropecuária Brasileira, Brasília, v.17, p.1127-1132, 1982.

VIEIRA, R. F.; CARDOSO, A. A. Variações nos teores de nitrogênio mineral em solo suplementado com lodo de esgoto. Pesquisa Agropecuária Brasileira, Brasília, v.38, p.867-874, 2003.

VIEIRA, R. F.; TANAKA, R. T.; SILVA, C. M. M. Utilização do lodo de esgoto na cultura da soja. Jaguariúna: Embrapa Meio Ambiente, 2004. 21p. (Boletim de Pesquisa e Desenvolvimento)

WEBER, C. R. Nodulation and non-nodulation soybeans isolines. I Agronomic and chemical attributes. Agronomy Journal, Madison, v.58, p.43-46, 1966. 